the college

\section{Guidance for the Use of Video Recording in Child Psychiatric Practice}

\section{Council Report CR79}

f5.00. 20 pp.

Videotape recording of interviews with patients and their families is now commonly used in child psychiatric practice. Involvement in videotape recording has a unique meaning for each patient and their family, and may potentially have a profound effect.

There are several purposes for the making of videotape recordings. The recording is based on a prior negotiation with the patient or a responsible adult, including verbal and written explanation and the gaining of formal consent.

This document outlines the procedures involved in videotaping, including ensuring confidentiality and obtaining consent. It provides guidance for all child and adolescent psychiatrists who are involved in the making and subsequent use of videotape recording. This new report replaces the previous document CR20, published in 1993

\section{Report of the Collegiate Trainees Committee Working Party on the Safety of Trainees}

\section{Council Report CR78 f5.00. 20 pp.}

Safety is of paramount importance to all psychiatrists. Just one piece of advice may make all the difference to you or to one of your trainees.

This Council Report contains practical advice on maintaining personal safety and sets standards for safety training, interview rooms and on-call accommodation. Recommendations are made about safety training for use on trainees' induction days and for the development of local policies and procedures on safety. Guidance is given about what to do in the event of an assault.

This document is essential reading for all educational supervisors, scheme organisers, trainees and anyone interested in personal safety in the field of psychiatry.

\section{Good Medical Practice in the Psychiatric Care of Potentially Violent Patients in the Community}

\author{
Council Report CR80.
} f5.00. 24 pp.

This new Council Report updates and replaces CR12, Good Medical Practice in the Aftercare of Potentially Violent or Vulnerable Patients Discharged from Inpatient Psychiatric Treatment, published in 1991. The scope of this new report is somewhat broader than the 1991 document, as it was considered to be important to recognise that the care necessary for such patients is not only applicable following discharge from hospital. The report outlines current statute and common law and incorporates guidance from the Department of Health, General Medical Council and other pertinent documents including inquiry reports.

Guidance is given on risk assessment and management, the relevant factors in the history, mental state examination, physical health, socio-environmental factors and response to treatment being outlined. Particular times (such as admission, discharge or transfer of patients) or events that may increase risk are delineated. The role of the psychiatrist in the process is described. Areas of particular concern such as patient confidentiality, clinical governance, training and factors that may adversely affect judgement are also demonstrated.

\title{
obituaries
}

\section{Leslie Allen Guile \\ MBChB DPM FRANZCR \\ FRCPsych}

Leslie (Les) Allen Guile died suddenly at the age of 78 years on 4 February 2000 from a ruptured aortic aneurysm.

At the time of his death he was working on an autobiography of his time as Flying Officer (Meteorologist) in the Royal Air Force (RAF) during World War Two and hoped to write a biography of the British composer Edward Elgar, whose work and life fascinated him.

Les was born in Wallasey in 1921 attended Wallasey Grammar and then saw war service in the RAF in England (Bomber Command) and later in India, and was awarded a Mention in Despatches. After the war he studied Medicine at the University of Liverpool, where he graduated MBChB in 1952. His interest in psychiatry was aroused early: he worked as senior house officer at Walton Hospital Psychiatric Unit 1953-1955. He moved from England to Melbourne, Australia, in 1955 and took up an appointment with the Victorian Mental Health Authority, working in acute and long-stay hospitals

He obtained the DPM (Melbourne University) in 1959. In all his appointments with the mental health authority he showed tremendous interest in psychotherapy and proved to be a born teacher in all areas of psychiatry, not only to his fellow medical officers but nursing and other staff too. He was a lecturer at the Victorian Police College, the College of Nursing, the Victorian Hospital and Charities Commission Training Unit and at Melbourne University, for the DPM course. Whether in staff conferences, formal lectures, informally over a cup of tea or waylaid in corridors, he showed grace, immense patience and enthusiasm, characteristics that he never lost.
He became a Foundation Member of the Royal Australia and New Zealand College of Psychiatrists (RANZCP) in 1963. He was appointed Foundation Member of the Royal College of Psychiatrists in 1971 and elected Fellow of the RANZCP in 1975. He was elected Fellow of the Royal College of Psychiatrists in 1979. He moved to Sydney, New South Wales (NSW), where he became senior staff specialist at Prince Henry Psychiatric Unit, 1968-1981. He was also clinical director 1968-1975. In addition, he was appointed conjoint senior lecturer, School of Psychiatry at the University of NSW, in 1971 and visiting consultant psychiatrist for the NSW Department of Corrective Services 1969-1973. He especially enjoyed working with the group psychotherapy programme at Prince Henry Hospital from 1978-1981. Later he moved into private consultant practice in 1981, then into the NSW Department of Health as Consultant in Child and Adolescent Psychiatry on the 